\title{
Validation of High-Resolution CFD Method for Slosh Damping Extraction of Baffled Tanks
}

Dr. H. Q. Yang/CFDRC/ESSSA

Dr. Jeff West/ER42/NASA

Presented at

AIAA Propulsion and Energy

25-27 July 2016

Salt Palace Convention Center

Salt Lake City, Utah 


\section{Phenomena}

- Oscillations of the free surface of a liquid in a partially filled tank

\section{Significance}

- Potential source of disturbance that may affect the stability and structural integrity of space vehicles.

- Can circulate sub-cooled propellant near the liquid vapor interface resulting in increased condensation and corresponding pressure collapse. Conversely: rapid vaporization and pressure rise near heated wall.

- Concern for propellant surface orientation during Upper Stage burn (to ensure sufficient liquid propellant for engine firing).

\section{Driving Mechanisms}

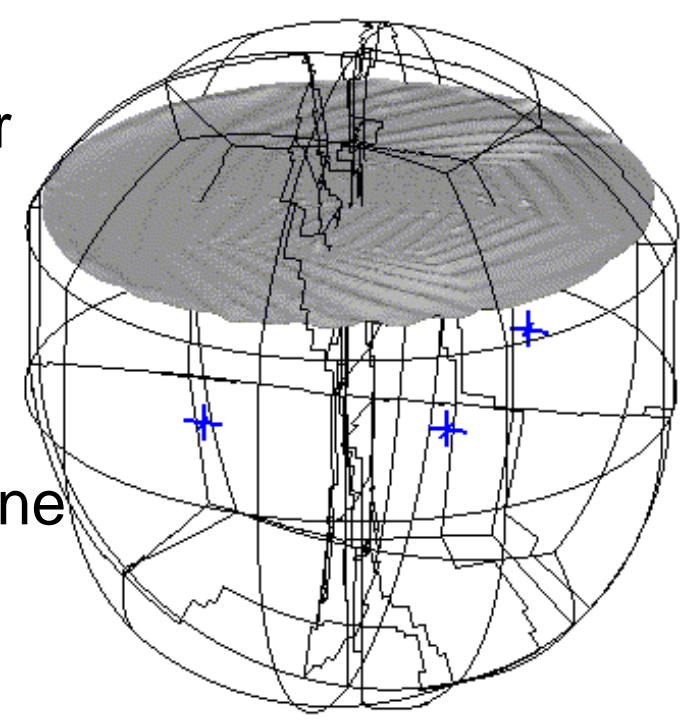

- The driving slosh forces: lateral disturbance, oscillatory thrust force (TO), angular rotation during maneuverings.

- It occurs during vehicle taxi, takeoff, engine shut off, and flight maneuvers. 


\section{8: ARES I} Smooth Wall and Ring Baffle Verification Validation

1956:

Empirical Methods SP-106, etc.
2012: Technical Excellence Non-Linear Slosh Damping Concept and Prediction 2013: Technical Excellence Non-Linear Slosh Damping Validation

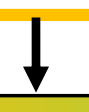

2015: NESC

Exploitation of NonLinear Damping for SLS/EUS Tanks

2014-16: CATALYST Spherical Tank Slosh Model including Linear and NonLinear Regimes
2016: Technical Excellence Integration of Improved Engineering Slosh Models

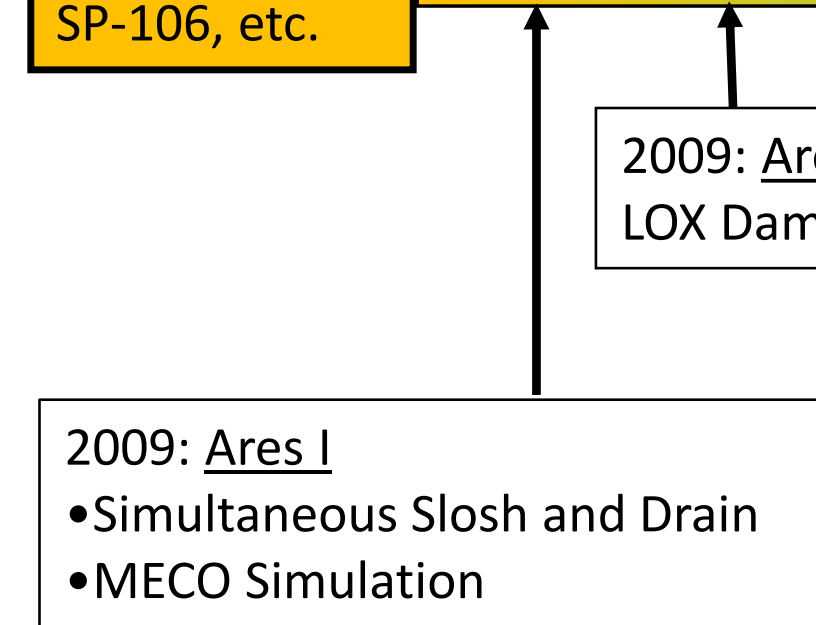

Increasing Engineering Capability for Propellant Slosh Abilities
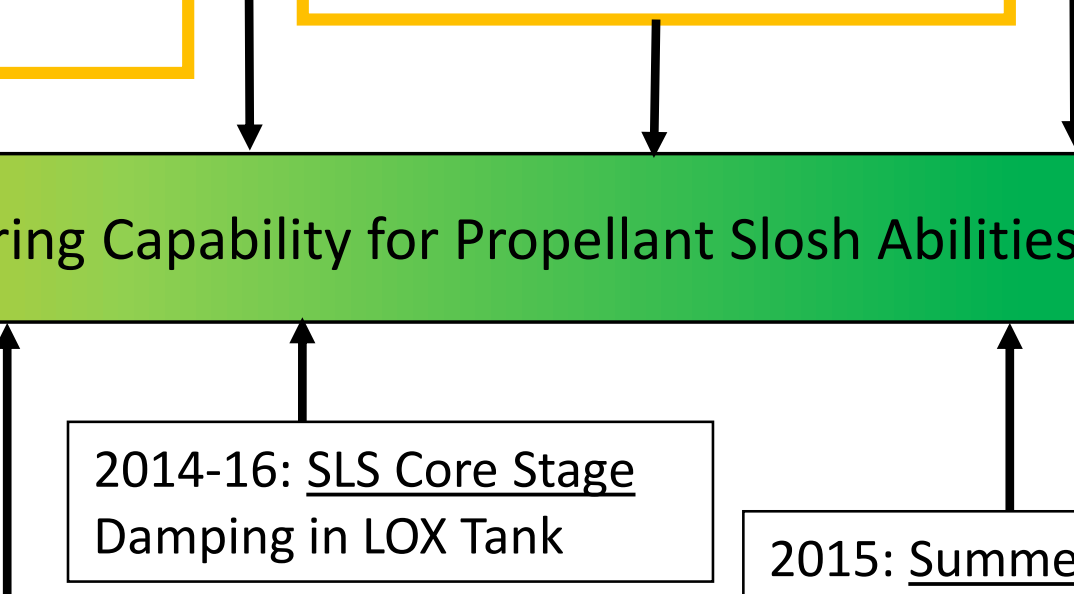

2014: Launch Services Program Ullage Effects due to High Amplitude Slosh
2015: Summer Intern

Program

Microgravity "Slosh"

Validation

Continuing interest from

LSP 


\section{Two Phase CFD Tool at ER42, CFD-ACE+}

- Well verified and validated for slosh frequency, mass, and mass center

- Yang and Peugeot, "Propellant Sloshing Parameter Extraction from Computational Fluid

Dynamics Analysis", J. of Spacecrafts and Rockets, 2014.

Table 1 Sloshing frequency comparison for water in a cylindrical $\operatorname{tank}(R=3$ in. $)$

\begin{tabular}{lcccc}
\hline \hline Liquid level & $h / R=2.0$ & $h / R=1.0$ & $h / R=0.5$ & $h / R=0.25$ \\
\hline Analytical & $2.4474 \mathrm{~Hz}$ & $2.3880 \mathrm{~Hz}$ & $2.0868 \mathrm{~Hz}$ & $1.6064 \mathrm{~Hz}$ \\
$\begin{array}{l}\text { Present CFD } \\
(80,000)\end{array}$ & $2.4485 \mathrm{~Hz}$ & $2.3832 \mathrm{~Hz}$ & $2.0822 \mathrm{~Hz}$ & $1.61 \mathrm{~Hz}$ \\
Error $(80,000)$ & $-0.1549 \%$ & $-0.201 \%$ & $-0.215 \%$ & $-0.822 \%$ \\
\hline \hline
\end{tabular}

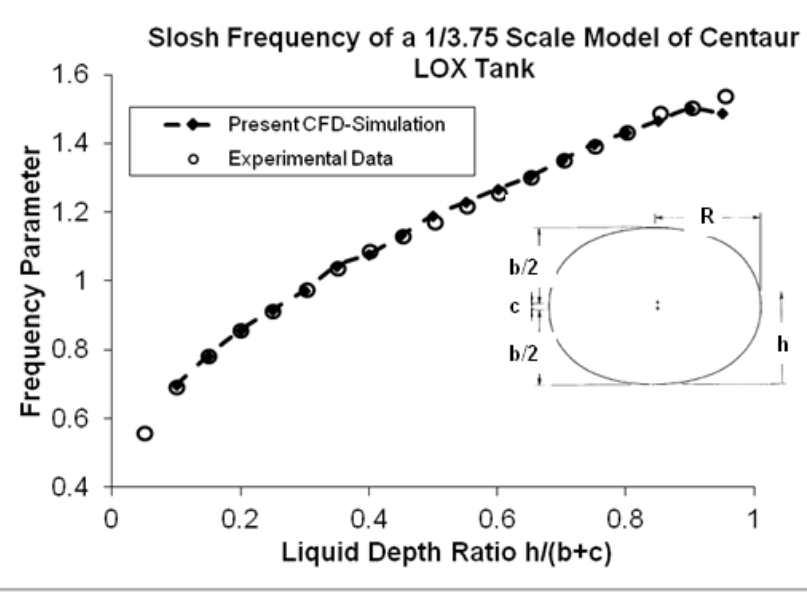

- Demonstrated and validated for surface break up.

- Preliminarily validated for damping due to ring baffle (by EV31 Ravi Purandare).

- Modeling smooth wall damping is a challenge

- Numerical damping for the solution stability could be larger than physical damping (from JPL results: $400 \%$ higher damping ratio, 0.03\% (empirical) vs. 0.13\% (Flow-3D).

- Boundary layer has to be well resolved.

- Numerical damping has to be estimated, and reduced to minimum.

- Our approach

. Fundamentally sound validation against experiments using smooth wall cylindrical tank.

Estimate numerical damping or find the techniques to remove/reduce numerical damping. 


\section{Experimental Data Collections}

For partially filled circular cylinder tank with smooth wall

- No analytical solution exists for slosh damping.

- Experimental data correlation only (liquid

height/R > 2) based on a set of experiments.

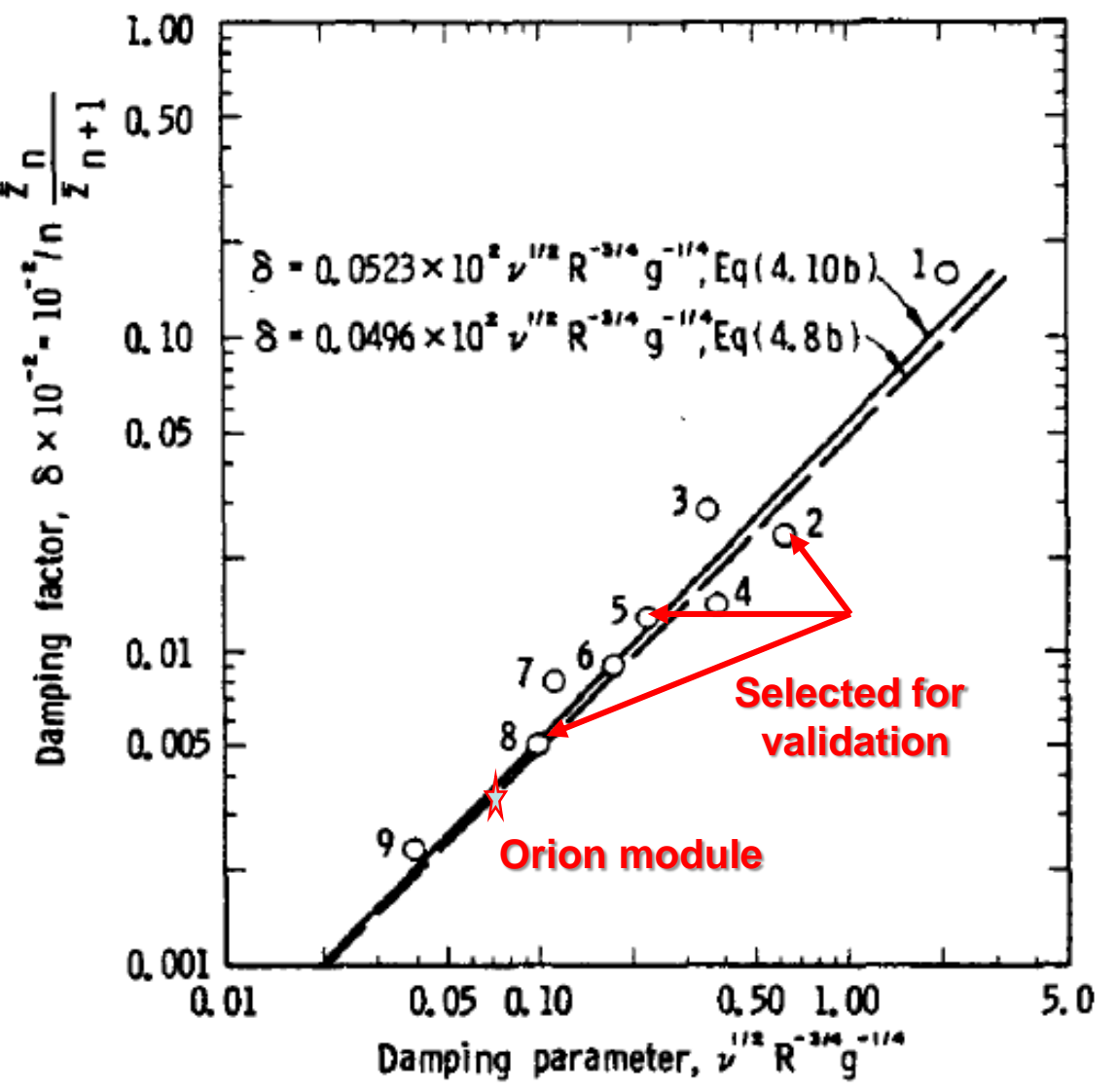

Test Conditions Selected for Validation:

- All in water

- Cylindrical tank with flat bottom surface

- Several radius of the tank to assess grid resolution effect.

- $\mathrm{R}=3.8 \mathrm{~cm}=1.5$ inch

- $R=15.2 \mathrm{~cm}=6.0$ inch

- $\mathrm{R}=45.7 \mathrm{~cm}=18$ inch

* Orion Service module: $\mathrm{R}=25$ inch

\begin{tabular}{|c|c|l|l|}
\hline $\begin{array}{c}\text { Data } \\
\text { point }\end{array}$ & $\begin{array}{c}\text { Tank radius, } \\
\text { cm }\end{array}$ & $\begin{array}{c}\text { Kinematic } \\
\text { viscosity, } \\
\text { stokes }\end{array}$ & \multicolumn{1}{|c|}{$\begin{array}{c}\text { Test liquid, } \\
\text { [reference] }\end{array}$} \\
\hline 1 & 15.2 & 0.836 & SAE 10 - W oil [4.13] \\
2 & 3.8 & 0.00929 & Water [4.4] \\
\hline 3 & 15.2 & 0.0223 & Kerosene [4.4] \\
4 & 7.6 & 0.00929 & Water [4.4] \\
5 & 15.2 & 0.00929 & Water [4.13] \\
\hline 6 & 38.1 & 0.0223 & Kerosene [4.13] \\
7 & 38.1 & 0.00929 & Water [4. 13] \\
8 & 45.7 & 0.00929 & Water [4.13] \\
\hline 9 & 152.5 & 0.00929 & Unpublished Convair / \\
& & & Astronautics data \\
\hline
\end{tabular}


Simulation Model: Half of the cylinder

Radius: 1.5 inch

Liquid Fill Level: 2R

Initial Slosh Amplitude: $0.05 \mathrm{R}$ (in linear regime)

Grid Type: Hexahedral

Grid Cell Numbers: 40K, 256K, 1M and 4M

Liquid Phase: Water; Gas Phase: Air

Boundary Conditions: non-slip wall on all sides and bottom; fixed pressure at top

Time Step Size: $C F L=0.1$; or $\mathrm{dt}_{\max }=0.5 \mathrm{~ms}$

Temporal Scheme: $2^{\text {nd }}$ Order Crank-Nicolson:

Spatial Scheme: $2^{\text {nd }}$ order Central $+1 \% 1^{\text {st }}$ Order

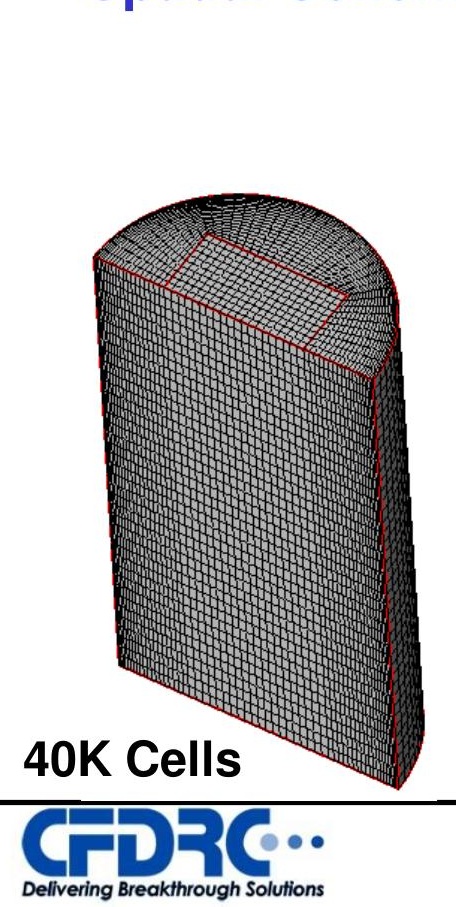

Increasing spatial resolution

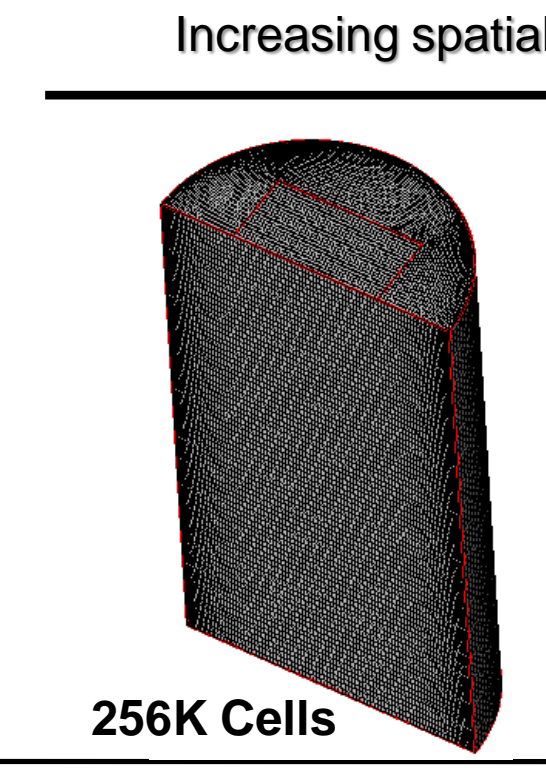

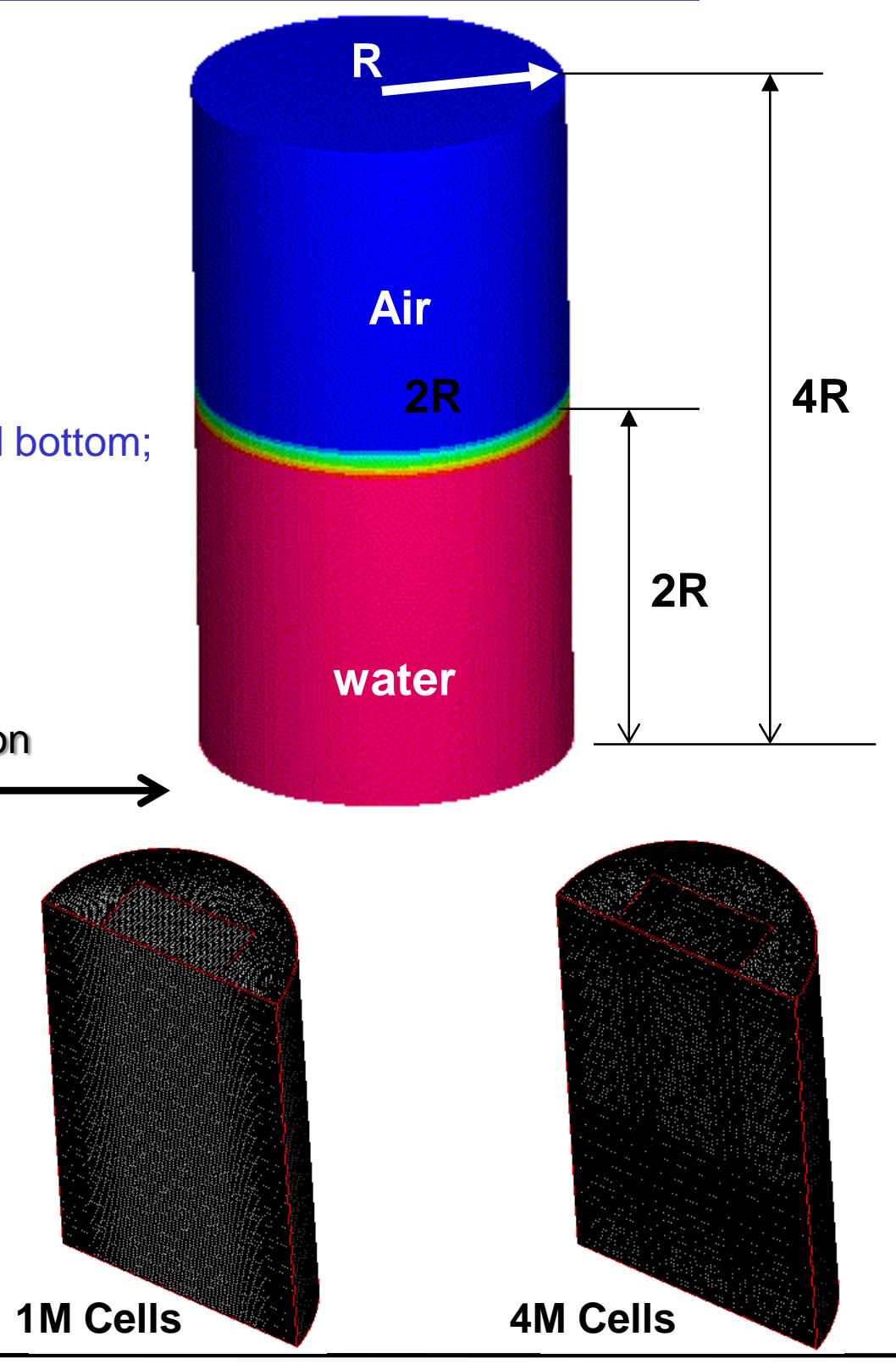




\section{Determination of Slosh Damping: A Very Challenging Task}

- No analytical solution exists. The damping physics involve the vorticity dissipation which requires full solution of the nonlinear Navier-Stokes equations.

- Previous investigations and knowledge were mainly carried out by extensive experimental studies.

- For any CFD tool, one must resolve a thin boundary layer near the wall and must minimize numerical damping.

\section{CFD Validation for Smooth Wall Cylindrical Tank of Different Sizes}

- Grid refinement study and comparison to experiment.

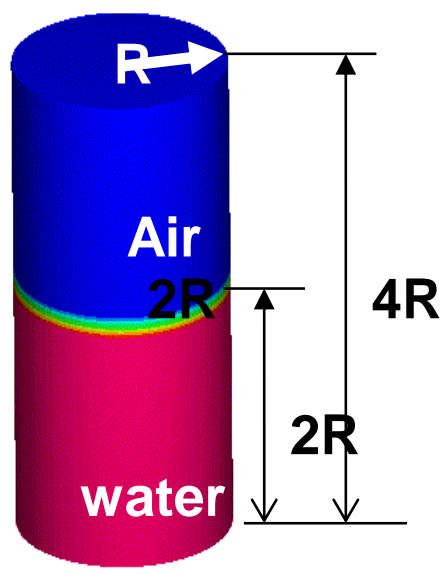

\section{- Grid resolution requirement}

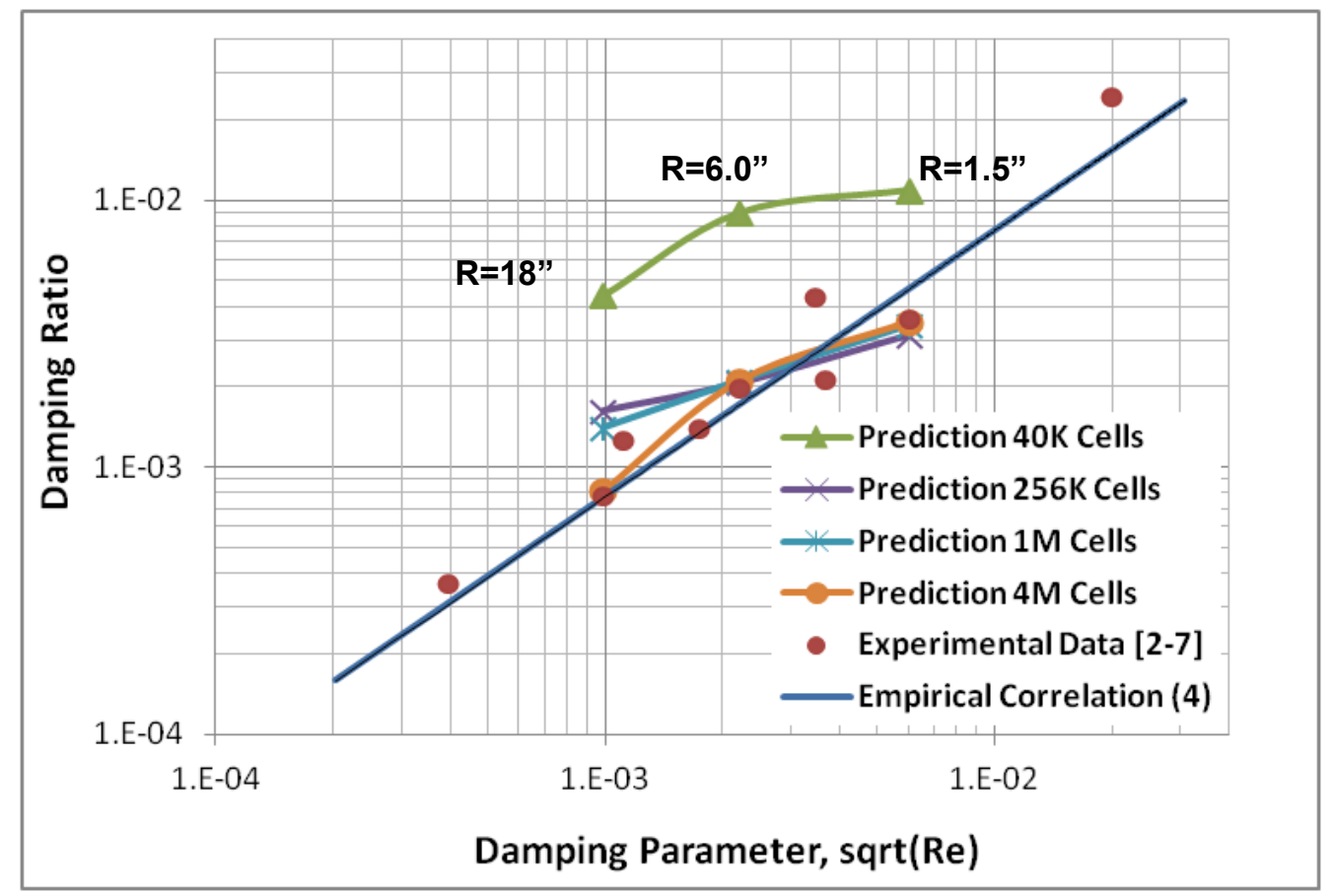

\section{Tank Radius}

$1.5 "$

6.0"

$18 "$
Required Total

Grid Size

256K

516K

$4 \mathrm{M}$
Root-Mean-Square Error:

Maximum Error:
$4.5 \%$ $5.5 \%$ 


\section{CFD Validation of Slosh Damping for a Smooth Wall Spherical Tank} -Spherical tank with $\mathrm{D}=43$ ", liquid fill height of $10 \%$.

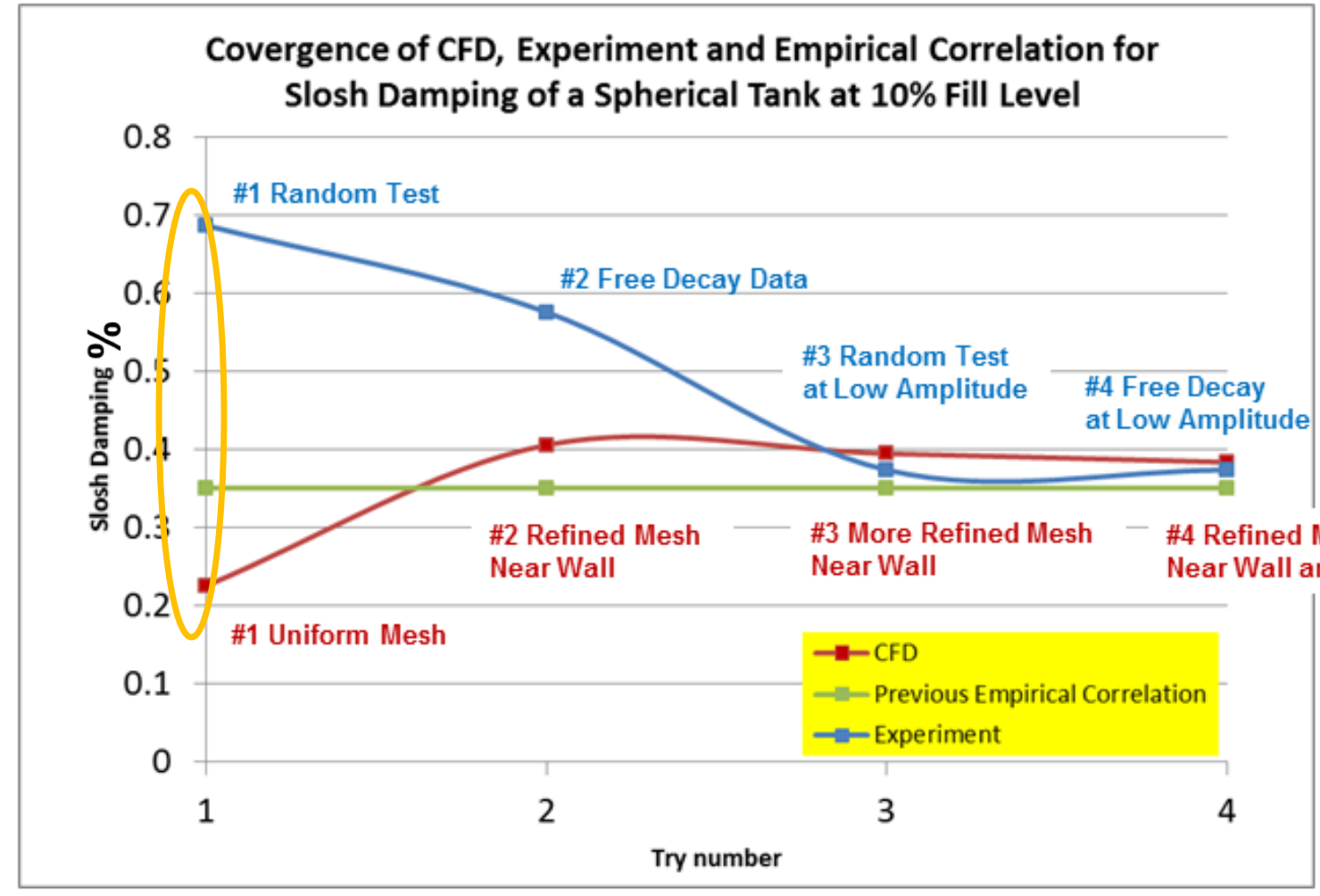

Error: $2.65 \%$

A successful validation requires close collaboration between analysis and experiment 


\section{Experimental Work of ET40 (June, 2011)}

- The tank model consists of a cylindrical barrel section and a spheroidal upper dome.

- 1/5 Ares LH2 tank.

- Tank radius: $21.56 "$

- Baffle location: 43.91"; width: 4.4".

- Liquid fill levels: 41" to 53".

- Test liquid: water

\section{Simulation Model}

- 5.7M Cells (based on our previous study using 4M cells for Orion smooth wall tank)

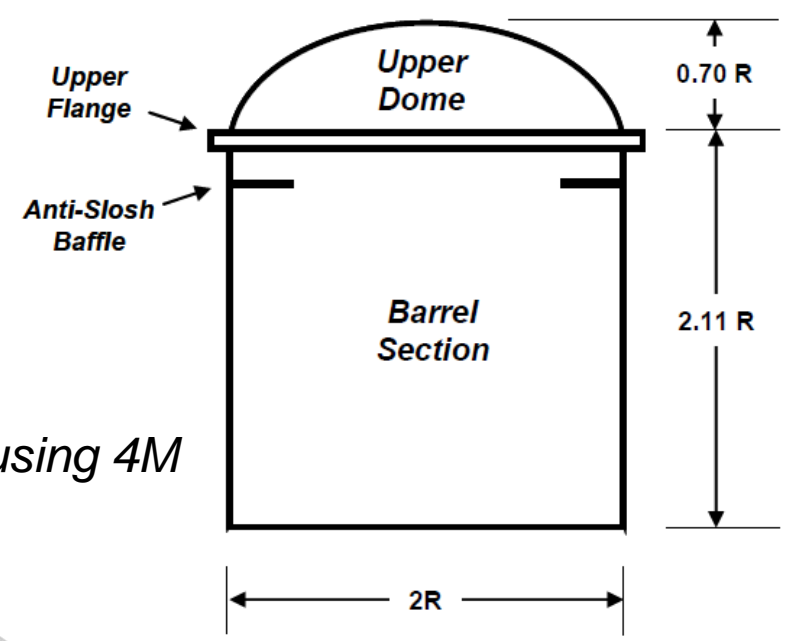

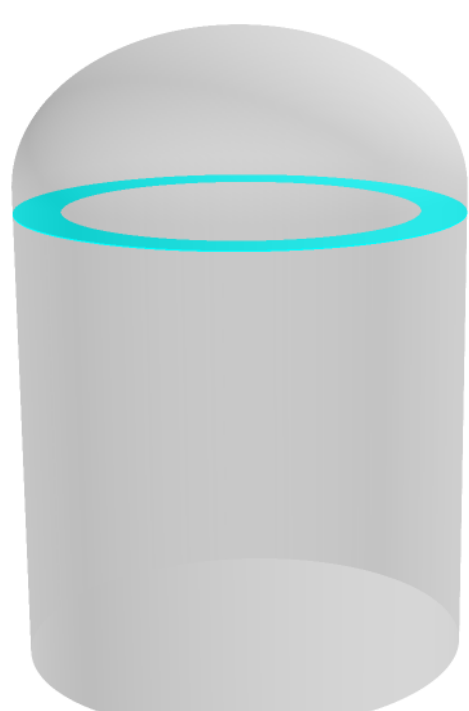

3D tank model

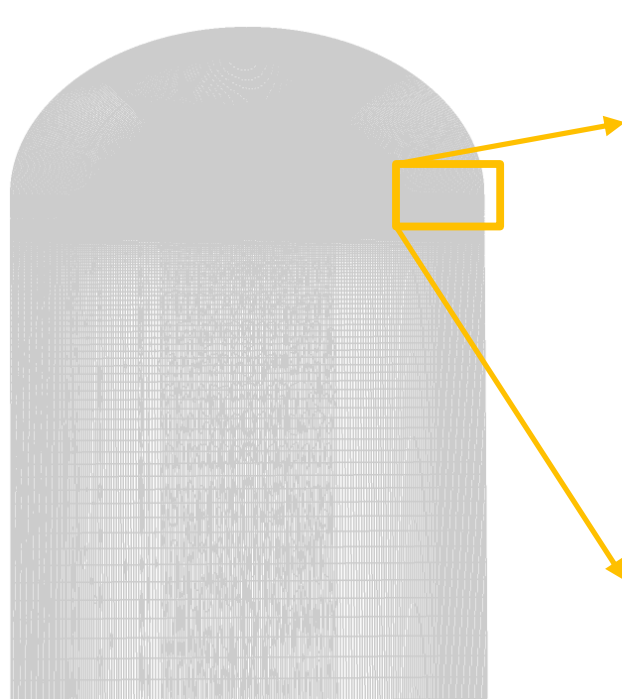

Grid around (above) and on (right) the baffle

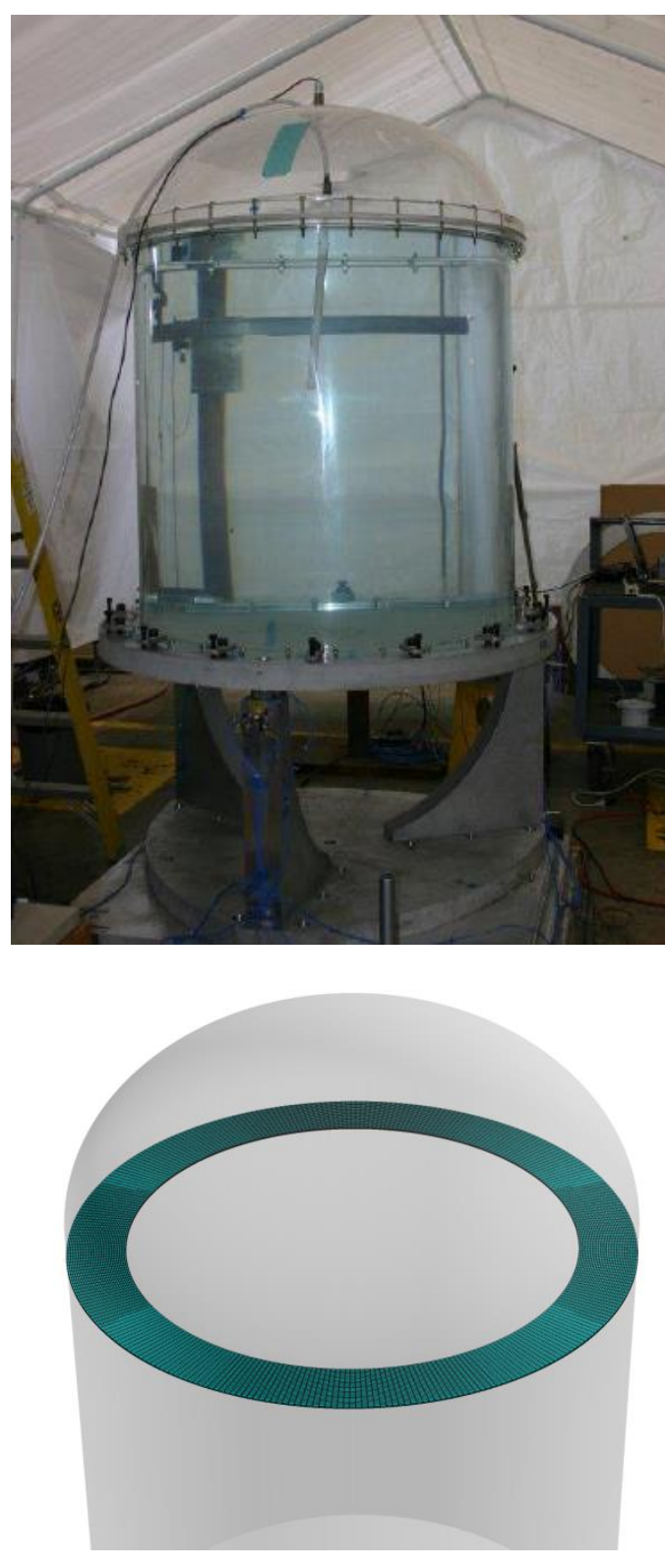




\section{Validation for a Straight Cylindrical Tank: Damping}

\section{For the Liquid Levels Below the Baffle, It is Slosh In a Cylindrical Tank}

- For the smooth wall damping: empirical correlation:

$$
\zeta=\frac{4.98}{2 \pi} * \frac{v^{0.5}}{\mathrm{R}^{0.75} g^{0.25}}\left\{1+\frac{0.318}{\sinh (1.84 \mathrm{~h} / \mathrm{R})}\left[1+\frac{1-\mathrm{h} / \mathrm{R}}{\cosh (1.84 \mathrm{~h} / \mathrm{R})}\right]\right\}
$$

- Previous smooth wall damping can be used for validation(again)

- This study: fill level effect; Previously: tank size effect.

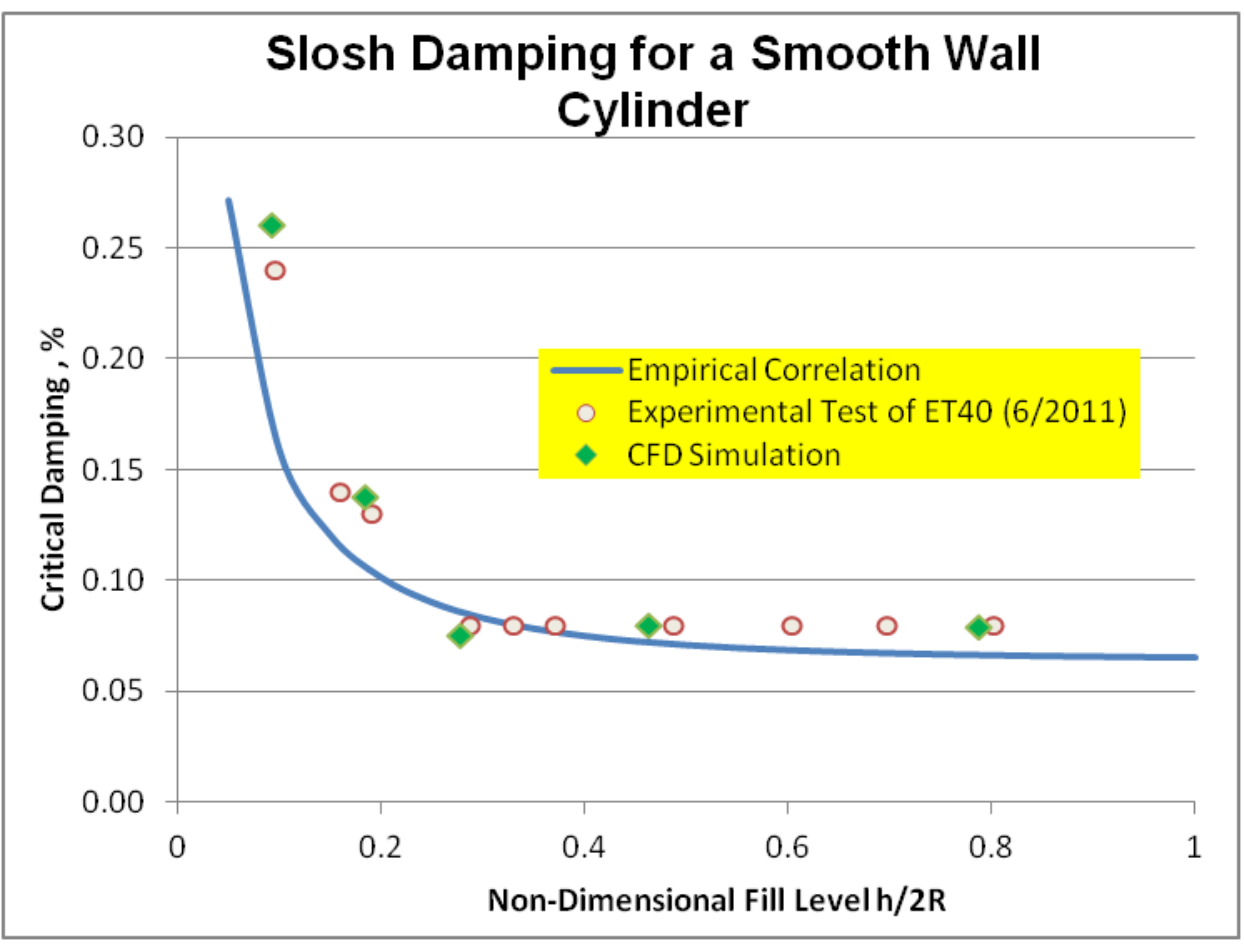

Observations:

- Very good agreements between all three for fill level above $h / 2 R=0.25$. CFD results agree with experimental data, except at the lowest fill level.

- For fill level $h / 2 R<0.25$, the empirical correlation under predicts damping. 


\section{Verification and Validation of Loci-Stream-VOF}

\section{Verification vs. CFD-ACE +}

- Grid Cells: 1 Million and 4 Million

- 2" Initial wave height.

- Orion Tank with Smooth Wall

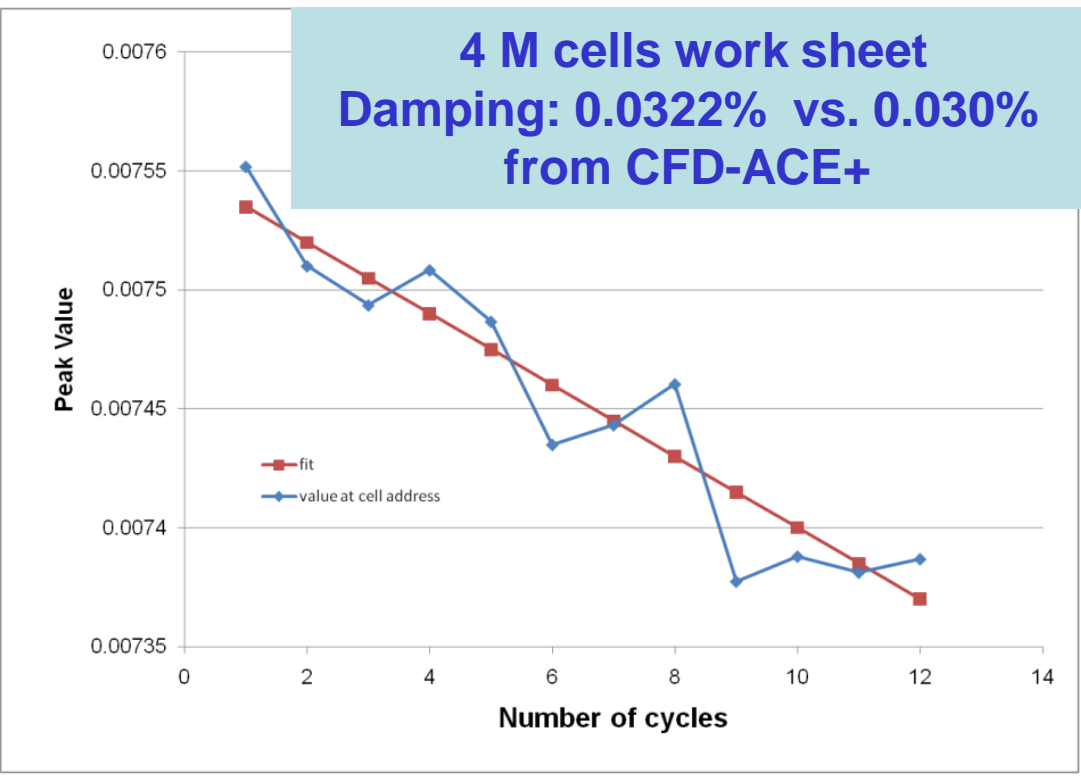

\section{Verification Achieved!}

Validation vs. ET40 Using $86 \%$ Orion Tank
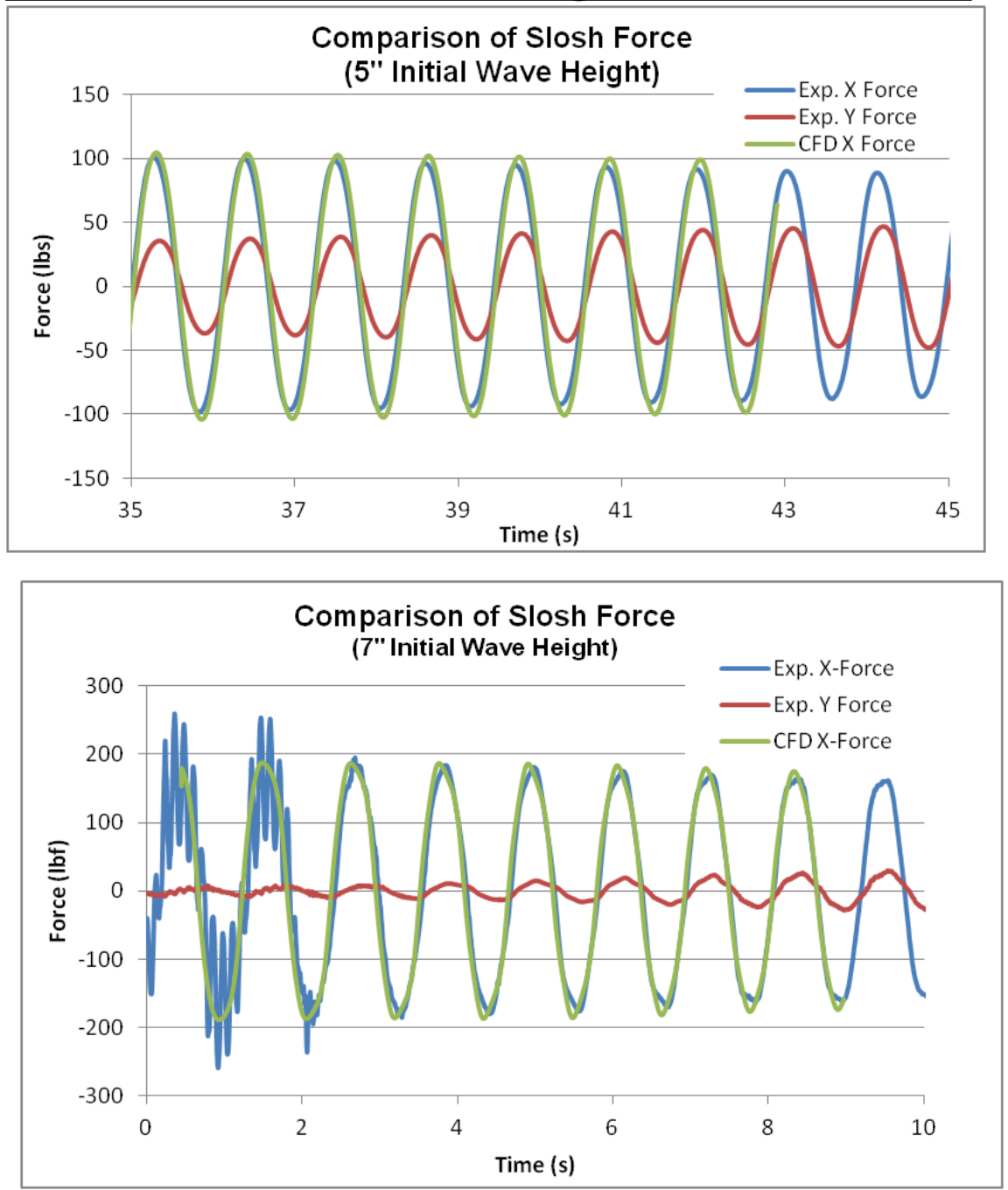


\section{Fill Level Right above Baffle $h=44.84 ", h_{B}=43.91 "$}

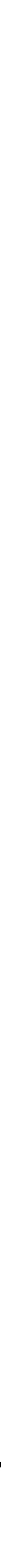




\section{Fill Level Above Baffle $h=45.56 ", h_{B}=43.91 "$}
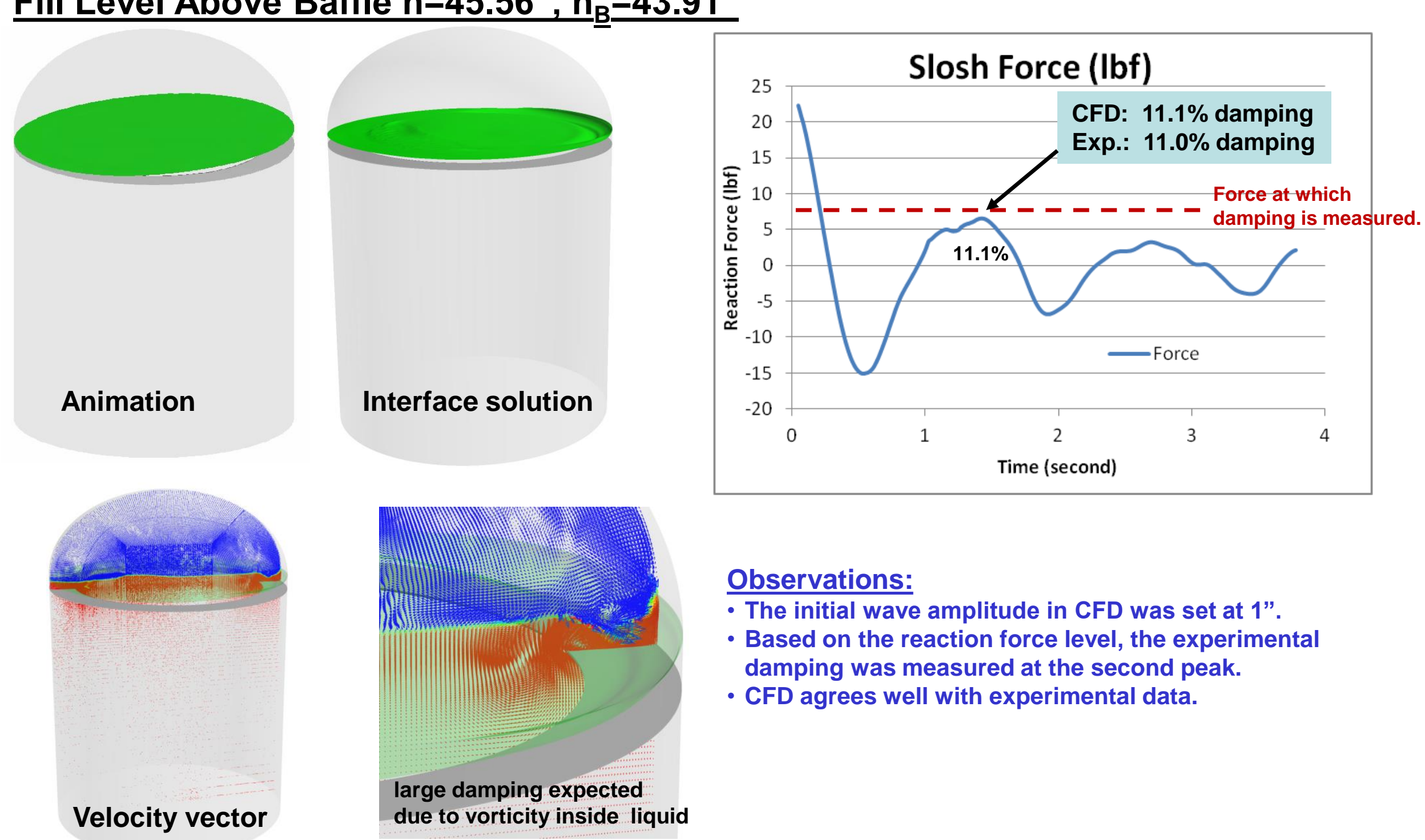

\section{Observations:}

- The initial wave amplitude in CFD was set at 1 ".

- Based on the reaction force level, the experimental damping was measured at the second peak.

- CFD agrees well with experimental data. 


\section{Fill Level Right above Baffle $h=46.64 ", h_{B}=43.91 "$}
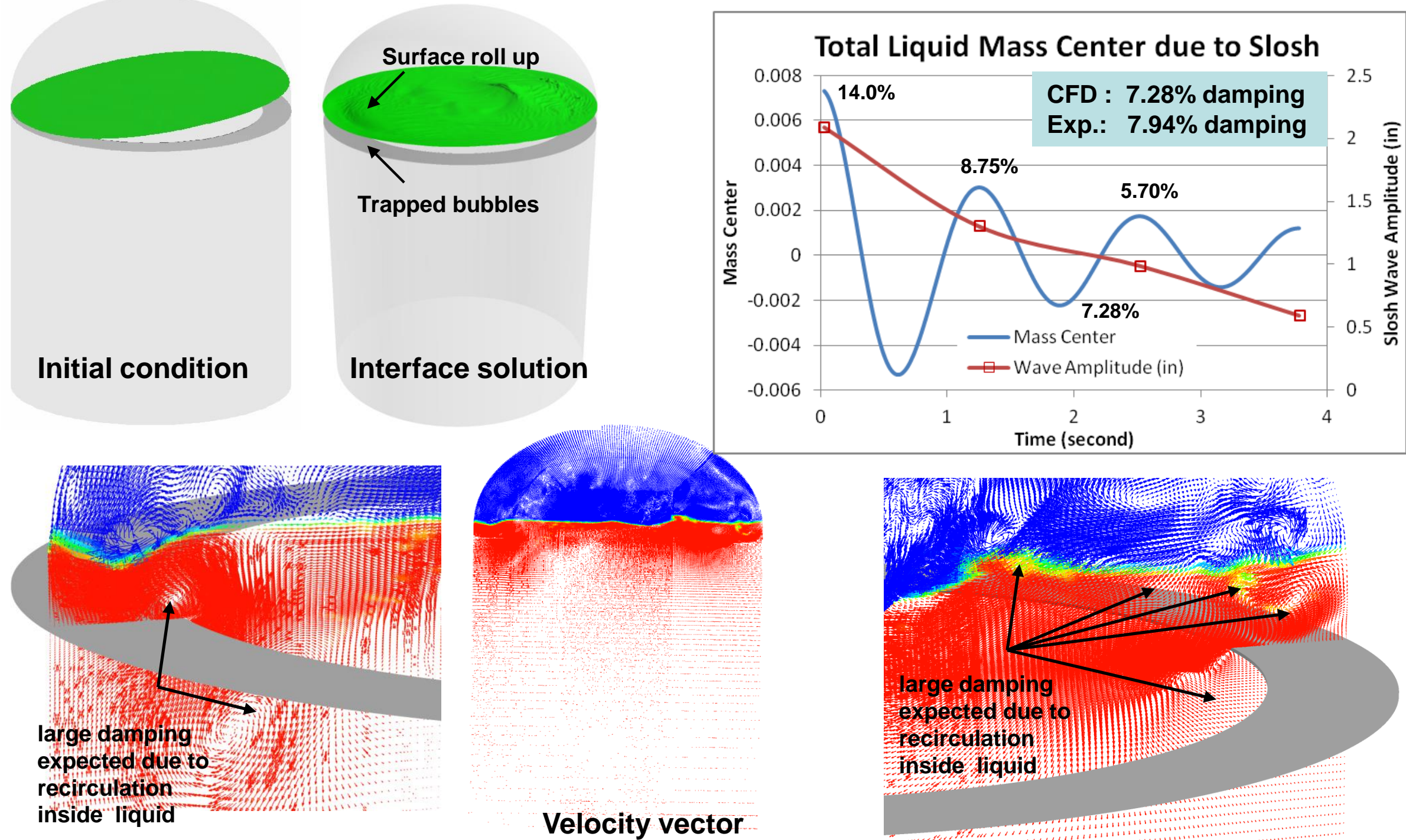

Velocity vector

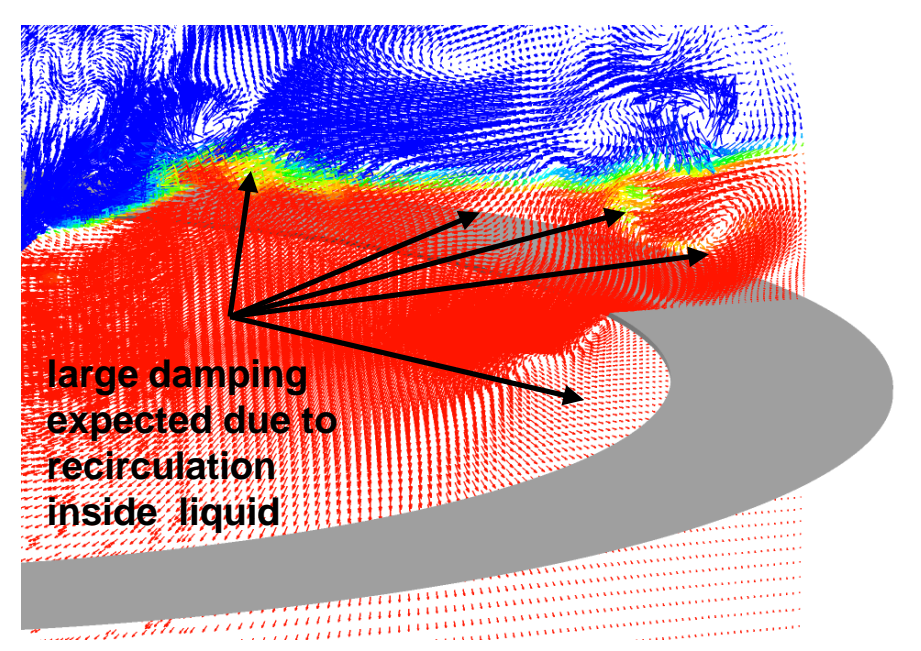




\section{Fill Level Above Baffle, $h=48.07^{\prime \prime}, h_{B}=43.91^{\prime \prime}$}

Higher surface wave modes

\section{Interface solution}

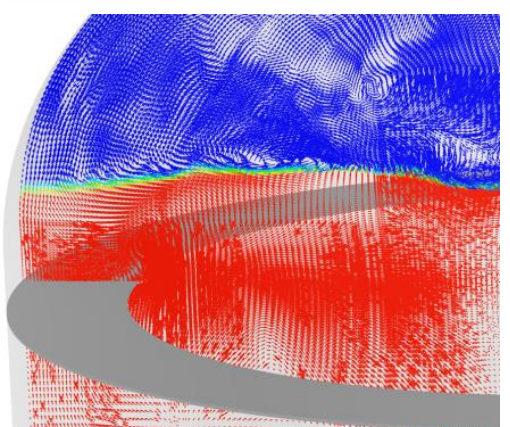

Recirculation zones inside liquid

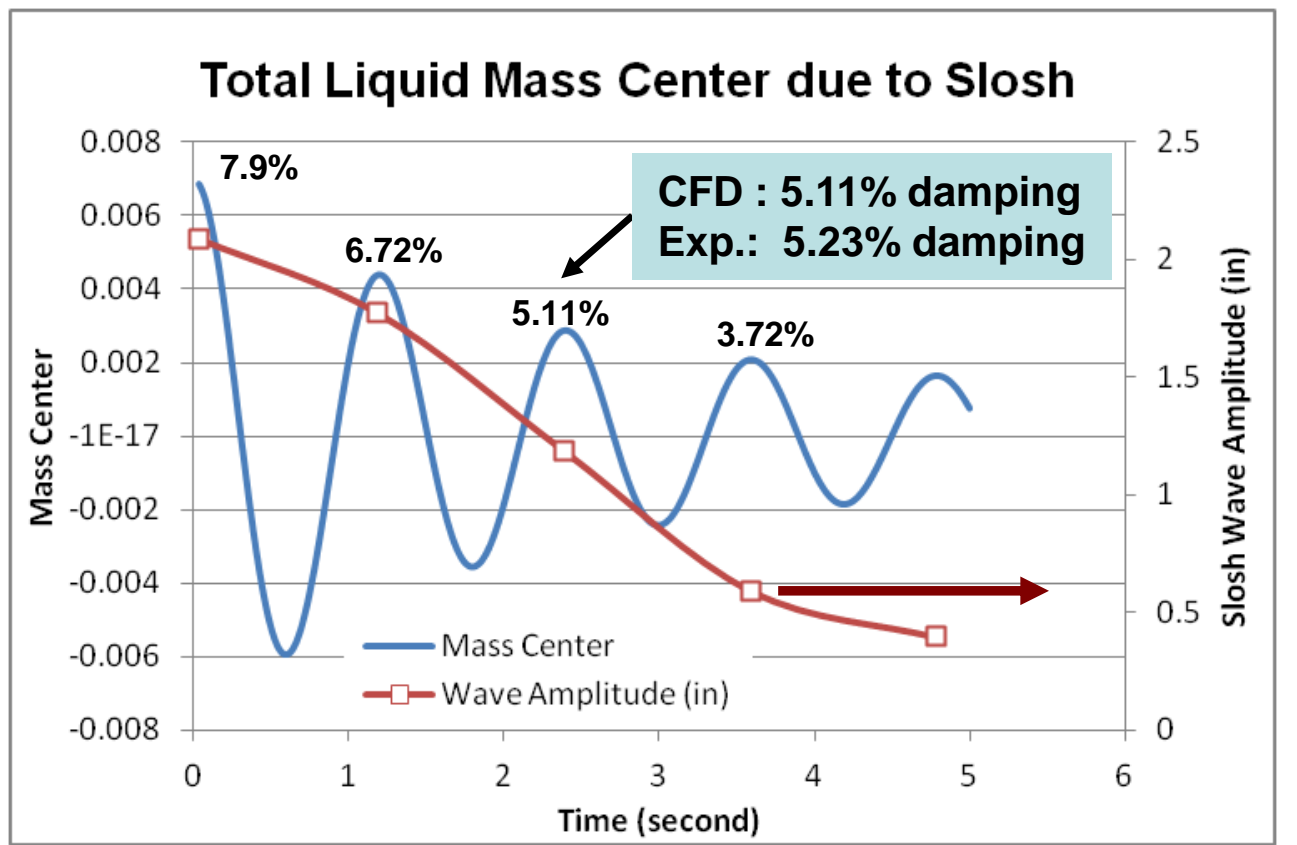

Observations:

- With the existence of baffle, the damping is a function of slosh amplitude.

- Very good agreements with experimental data at the same slosh amplitude of 1 "'.

- High damping comes from higher modes due to the interaction of surface wave with baffle and local circulations around baffle tip. 


\section{Fill Level Above Baffle, $h=49.16^{\prime \prime}, h_{B}=43.91^{\prime \prime}$}
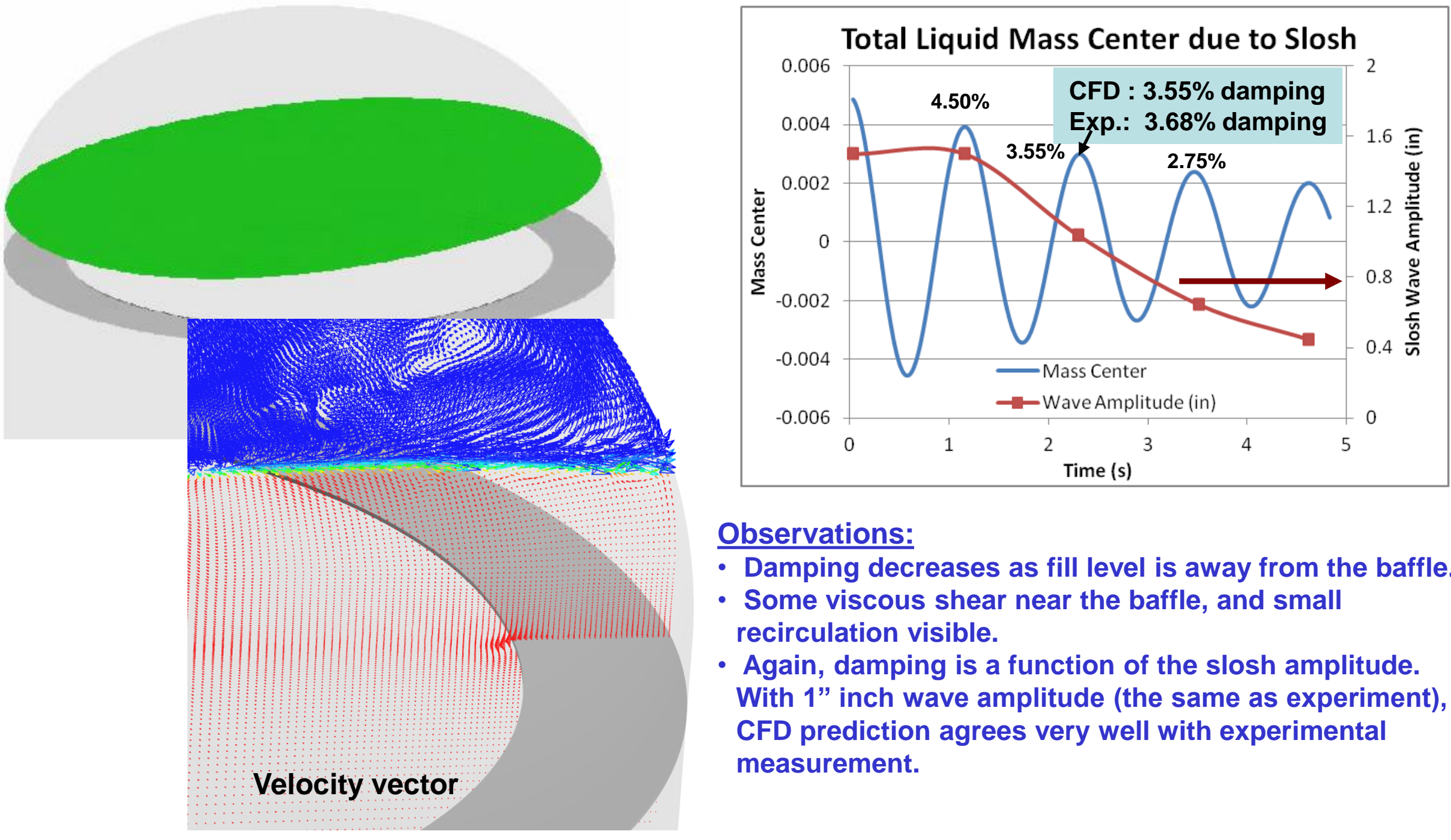

\section{Observations:}

- Damping decreases as fill level is away from the baffle.

- Some viscous shear near the baffle, and small recirculation visible.

- Again, damping is a function of the slosh amplitude. With 1" inch wave amplitude (the same as experiment), CFD prediction agrees very well with experimental measurement. 


\section{Fill Level in the Dome Section (Grid Refinement Study), $h=53.19{ }^{\prime \prime} h_{B}=43.91$ "}

- Grid refinement: $10 \%$ increase in each direction; from $5.7 \mathrm{M}$ to $7.4 \mathrm{M}$, and to $9.2 \mathrm{M}$.

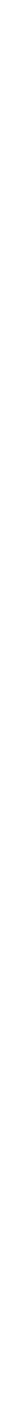




\section{Validation for Baffled Tank}

\section{Comparison of Experiment, Analysis (Miles' Equation by EV31) and CFD}

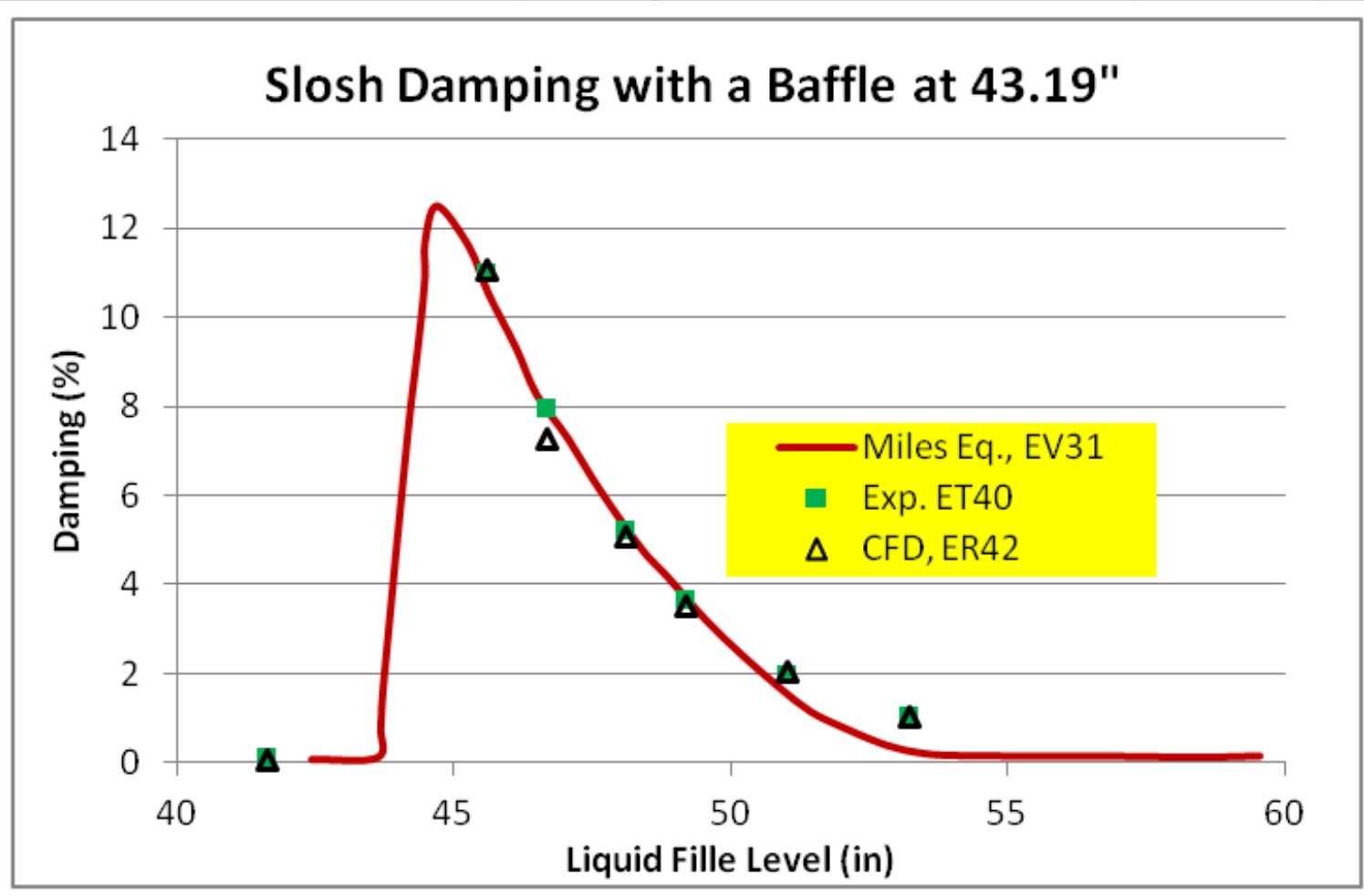

\section{Observations:}

- CFD results are in good agreement with experimental data at all fill levels, thus we conclude that using Loci-STREAMVOF with this procedure for the purpose of predicting Slosh Damping due to a Baffle is validated.

- Miles's equation predicts good fit to the experimental data. However, deviations occur in the dome section (high fill levels) 


\section{Summary}

- The predicted slosh damping values from Loci-Stream-VOF agree with experimental data very well for all fill levels in the vicinity of the baffle.

- Grid refinement study is conducted and shows that the current predictions are grid independent.

- The increase of slosh damping due to the baffle is shown to arise from:

- a) surface breakup;

- b) cascade of energy from the low order slosh mode to higher modes; and

- c) recirculation inside liquid phase around baffle.

- The damping is a function of slosh amplitude, consistent with previous observation.

- Miles equation under predicts damping in the upper dome section. 